\title{
Representaciones visuales y literarias en diálogo: el caos en los sectores sociales marginales del Costumbrismo de México y Cuba.
}

\section{Visual and literary representations in dialogue: chaos in socials and marginals sectors in Mexico's and Cuba's Costumbrismo.}

\author{
Jesús Adalberto Campaña Fimbres \\ Departamento de Letras y Lingüística / Universidad de Sonora (MÉXICO) \\ CE: jesus.c.fimbres@gmail.com ID ORCID: 0000-0002-6258-8204
}

DOI: $10.32870 /$ sincronia.axxiii.n76.29b19

\section{$\mathrm{BY} \cdot \mathrm{NC}$}

Esta obra está bajo una Licencia Creative Commons Atribución-NoComercial 4.0 Internacional

Recibido: 30/03/2019

Revisado: $20 / 05 / 2019$

Aprobado: 10/06/2019

\section{RESUMEN}

El Costumbrismo en América Latina tuvo una función social muy importante: unificar a la nación y crear un sentimiento de identidad dentro del territorio geográfico de países específicos. No obstante, no todas sus representaciones siguieron el mismo molde. En México, Claudio Linati realizó una serie de litografías acompañadas por artículos que publicó bajo el título Trajes civiles, militares y religiosos de México en 1828. En ciertos casos, se puede percibir que la litografía no desempeña un papel armónico con el artículo de costumbres: hay elementos que insinúan un comportamiento caótico y violento en algunos tipos sociales y culturales marginales del México dieciochesco. Este costumbrismo, guardando la distancia social y temporal, dialoga de una manera sugerente con algunas litografías sobre Cuba de Víctor Patricio de Landaluze, y con los artículos que acompañan a estas obras en el libro Tipos y costumbres de la Isla de Cuba de Bachiller y Morales y Landaluze. La 
línea temática que sitúa un diálogo en ambas expresiones es la insinuación de violencia y caos en sectores marginales.

Este trabajo realiza un análisis en los temas antes mencionados a través de las litografías y los artículos de costumbres y busca relacionar dos espacios geográficos distintos a raíz del costumbrismo, señalando sus similitudes y diferencias.

Palabras clave: Violencia. Linati. Landaluze. Perspectiva letrada. Litografía. Artículos de costumbres.

\begin{abstract}
:
Costumbrismo in Latin America had a very important social function: to unify the nation and create a sense of identity within the geographical territory of specific countries. However, not all the representations followed the same mold. In Mexico, Claudio Linati made a series of lithographs accompanied by articles published under the title Trajes civiles, militares y religiosos de México in 1828. In some cases, it's possible to perceive that the lithography does not play a harmonious role with the Costumbrismo articles: there are elements that suggest a chaotic and violent behavior in some marginal social and cultural types of eighteenth-century Mexico. This Costumbrismo, keeping the social and temporal distance, converses in a suggestive way with some lithographs about Cuba by Victor Patricio de Landaluze, and, also, with the articles that accompany these works in the book Tipos y costumbres de la Isla de Cuba by Bachiller y Morales and Landaluze. The thematic line that places a dialogue in both expressions is the hint of violence and chaos in marginal sectors.

This work analyzes on the aforementioned topics through lithographs and the articles and seeks to relate two different geographical areas of Costumbrismo, noting their similarities and differences.
\end{abstract}

Keywords: Violence. Linati. Landaluze. Literate perspective. Lithography. Costumbrismo articles.

Una de las vertientes más importantes del costumbrismo es la representación de tipos sociales. Hispanoamérica no fue la excepción si se habla de reproducir a distintos grupos de la población que se distinguen por una característica en particular. Uno de los rasgos que dota al costumbrismo 
literario de vetas importantes para su estudio es su constante comunicación con las expresiones visuales, como la litografía y la pintura. Entre la considerable variedad de ilustraciones de tipos sociales, posiblemente una de las más importantes por sus implicaciones sociopolíticas es la de los sectores marginados. El objetivo de este trabajo es analizar las implicaciones que poseen algunas obras visuales de los artistas Víctor Patricio de Landaluze en Cuba y Claudio Linati en México, en relación con las expresiones literarias que las acompañaban en la mayoría de los casos. El material de trabajo analizado en el presente estudio consiste en dos libros de artículos y litografías: Tipos y costumbres de la isla de Cuba (1881) de Bachiller y Morales y Landaluze, y Trajes civiles, militares y religiosos de México (1828) de Claudio Linati. Además, se utilizará una pintura titulada Día de Reyes en La Habana de Landaluze y un poema ${ }^{1}$ sobre la misma festividad. A partir de estas disciplinas artísticas se puede observar una constante: existen elementos suficientes que pueden dar pie a asociar a los sectores marginales con el caos, el desorden y la violencia. Si bien en el caso de Linati el diálogo que se establece entre la ilustración y el artículo es, de cierta manera, dicotómico, presenta una apertura de análisis compleja y abierta a interpretaciones. El costumbrismo en México y Cuba es, por tanto, interesante por los distintos tratamientos que se presentan entre una y otra tradición de un fenómeno que las abarca a ambas.

Ana Peñas Ruiz (2011) menciona la relación entre las representaciones visuales con la literatura, señalando su importancia en conjunto:

De todos los principios vertebradores de la poética costumbrista, el vínculo explícito que establece con la pintura es uno de los que mejor la definen [...] los escritores de costumbres [...] se alinean en un antiguo paradigma dialéctico entre poesía y pintura [...]. (P. 625).

La hermandad existente entre imagen y literatura no resulta, por tanto, ajena a su estudio. Es pertinente analizar los vasos comunicantes que establecen entre sí. Al ser dos expresiones artísticas los textos comienzan a dialogar.

\footnotetext{
${ }^{1}$ Miriam Escudero se lo atribuye a "un tal Vicente". La información bibliográfica se encuentra en el apartado de Referencias.
} 
Antes de comenzar, es necesario realizar un apunte fundamental para este análisis: el miedo del sector letrado a las agrupaciones marginales que implican, en la mayoría de los casos, según su perspectiva, desorden. El ejemplo que mejor lo representa es el del cuadro de costumbres de "Los mataperros" de Landaluze, que será analizado más adelante. Las masas y la falta de control se vuelven una amenaza a los intentos de orden que se esbozaban a lo largo del siglo XIX. La existencia de estos sectores marginales, considerados como amenazas desperdigadas en la sociedad, representaba un golpe a la estabilidad.

En Trajes civiles, militares y religiosos de México (1828), Claudio Linati busca exponer los distintos tipos sociales existentes en México en la primera mitad del siglo XIX. De ellos, resulta importante, como se ha mencionado, el tratamiento que se realiza de algunos grupos marginales. No sólo se percibe una intención en la litografía sino, también, en el texto que la acompaña. Es necesario mencionar que los elementos que aparecen alrededor de los personajes influyen en su interpretación, ya que estos se incluyen arbitrariamente. Al contrario, les imprimen una carga, en la mayoría de los casos, negativa. En las siguientes figuras (Figura 1 y Figura 2) se puede observar la intención de Linati al ilustrar a los mencionados sectores. En este caso dos mujeres indígenas en medio de una pelea y al lépero. 
Figura 1

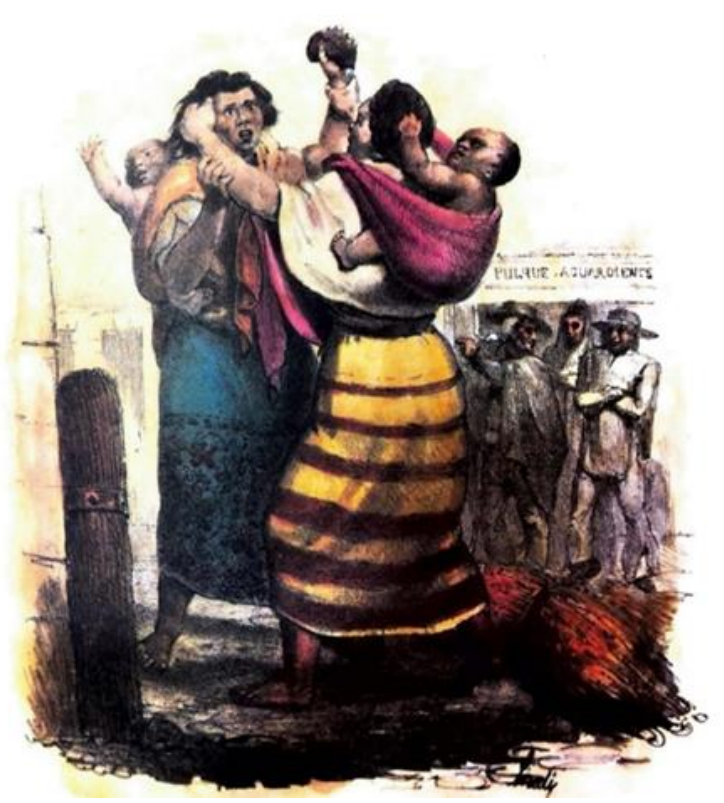

Claudio Linati. "Pleito de dos indias". Extraído del libro Trajes civiles, militares y religiosos de México (p.77).

Figura 2

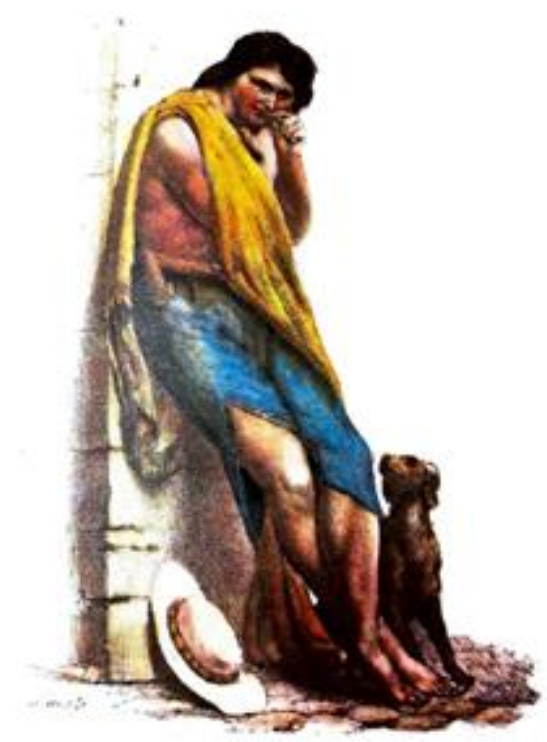

Claudio Linati. "Lépero - Vagabundo". Extraído del libro Trajes civiles, militares y religiosos de México (p.29). 
Como es posible observar en las ilustraciones, uno de los aspectos que sobresale es el cartel al fondo de la figura 1. Este indica la venta de distintas bebidas alcohólicas como el pulque y el aguardiente, lo cual implica una carga negativa: el descontrol de los sentidos, por ejemplo. Además, la multitud que se encuentra visualizando la pugna, tiene una significación de desorden que se complementa con los niños que penden de las espaldas de sus madres, asustados por los movimientos bruscos. Estos componentes le atribuyen rasgos negativos a la configuración de las mujeres indígenas. La figura 2, si bien no muestra indicios de violencia, tampoco es libre al momento de insinuar predicaciones peyorativas. En distintas litografías de la época, en las que se caracteriza a los grupos sociales del margen, es común ver un perro callejero que convive con ellos. Esto se asocia al desorden en el que se ven inmersos estos personajes. De una u otra manera, la litografía sugiere una unión animal-humano en la que, aparentemente, no hay una diferenciación entre ambos. Esto implica una representación del ser humano, aunque irónico, deshumanizado, que adquiere predicaciones irracionales. En este caso, el lépero es despojado de la razón y se vuelve un ser instintivo. Al ir descalzo, de igual manera, se puede observar la intención de atribuirles poca civilización, si esta es vista desde una perspectiva occidental. Por tanto, resulta verdaderamente sugerente cada elemento que compone la obra. No obstante, también es interesante el artículo de costumbres, homónimo en todos los casos, en el que Linati no condena dichas práctica o formas de vivir sino que encuentra una manera de, si no justificar el acto, comprenderlo. Lo anterior se percibe en el siguiente fragmento de "Pleito de dos indias":

Si América nos ha hecho funestos obsequios, Europa con sus licores fermentados, se ha vengado en demasía. La embriaguez, desconocida por los antiguos habitantes del Anáhuac, multiplica ahora sus cuadros desagradables sobre la base de la inocencia y la sencillez [...]. (Linati, 1981, p. 76).

Como se puede observar, hay una gran diferencia en la interpretación de ambos textos si se analizan de manera individual. Linati hace lo posible para encontrar una razón que redima a las 
clases bajas por caer en la violencia. En esa línea de pensamiento, es posible notar una carga de afecto del autor hacia los representados. Ya sea resaltando su ingenuidad e inocencia o culpando a los españoles de este tipo de problemáticas, se demuestra una intención que contrasta con el cuadro visual. El artículo que acompaña a la figura 2, si no afirma que el ser vagabundo es útil a la sociedad, tampoco lo condena con repulsión o rechazo:

Si el veneno de la corrupción y el fanatismo no excitaran su corazón sencillo y su espíritu estrecho [...] y si sus necesidades artificiales no lo hicieran algunas veces, instrumento dócil en las manos del despotismo y de la superstición. (Linati, 1981, p. 28).

De manera recurrente el personaje se ve condenado en la imagen. Sin embargo, en el artículo se describe de una manera cariñosa y se puede ver una comprensión y un tono de lástima por el tipo social. Esto, al igual que "Pleito de dos indias", nos habla de que ambos cuadros se complementan entre sí. Linati presenta una perspectiva que intenta comprender y enriquecer la construcción de una sección de la población marginal.

Este choque, lejos de ser un aspecto negativo, abre, como ya se ha mencionado, una categoría de análisis distinta: la comunicación entre ambas disciplinas es útil para interpretar cómo se construye a un tipo social. Además, como menciona Bobadilla Encinas (2013, pp.117-118):

[...] hay una perspectiva empática con los caracteres y las situaciones que se asumen como típicos, pues hay una tendencia a explicar sus características y significaciones positivas como parte de la naturaleza propia del mexicano (sea el indio, mestizo o criollo), en tanto que sus particularidades y cualidades negativas son entendidas y explicadas como herencia e influencia española, europea [...]

Es interesante la postura ética que caracteriza a Claudio Linati, especialmente con los sectores marginales. No obstante, como se verá más adelante, no en todas las litografías y artículos se puede percibir esa empatía que sí se destaca en estas representaciones. Por otro lado, el caso de Cuba es particularmente interesante para la comunicación entre ambas disciplinas artísticas. Víctor Patricio de Landaluze colaboró con sus litografías en el libro Tipos y costumbres de la isla de Cuba, que 
abarca tanto litografías como artículos de distintos autores de la época. Al respecto, Olga María Rodríguez (1998) menciona lo siguiente: "La obra reflejaba a distintos tipos populares que circulaban por las localidades y le daban vida con su folclorismo, sus atavíos pintorescos y su hormigueante ajetreo" (p.85). Los trabajos litográficos y literarios distan de la empatía que sí se percibe en Linati. Estos buscan moralizar y utilizan la litografía que, además de introducir el folclore que menciona Rodríguez, sirve de pretexto al sancionar moralmente a ciertos tipos sociales. El caso "Los mataperros" (Figura 3) de Landaluze es uno de los ejemplos que incluye esa línea de pensamiento de los costumbristas cubanos. Es posible percibir elementos que sugieren un desorden y caos de este grupo característico de la isla de Cuba decimonónica.

Figura 3

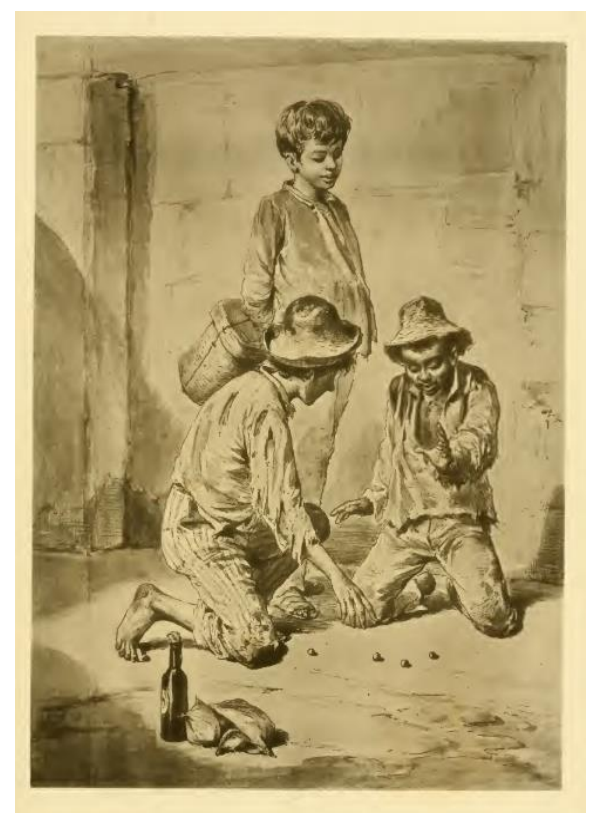

Víctor Patricio de Landaluze. "Los mataperros". Extraído del libro Tipos y costumbres de la isla de Cuba (p. 193).

Como se puede apreciar, es posible entender cuál es la intención de ilustrar al mataperros de la manera en que se hace. El primer rasgo que contrasta con la armonía es, sin duda, la aparición de niños. La manera en que se busca configurarlos no es inocente y desinteresada: la infancia, que en 
muchos casos representa inocencia y bondad, no se percibe de esa manera. Características que ayudan a construir una imagen de desorden y caos son las botellas que aparecen a un lado de los niños: el alcohol es fundamental si se trata de cargar despectivamente a un colectivo. El ocio, al igual que las bebidas alcohólicas, es utilizado para proyectar una imagen de desorden en la sociedad, uno de los problemas más denunciados en la época. Además, lo poco civilizado, bajo una perspectiva letrada, que lucen los mataperros se apoya en los pies descalzos de los niños. Este aspecto contribuye peyorativamente a su construcción. El artículo homónimo escrito por José Joaquín Hernández establece un diálogo con la litografía, pues se percibe la misma intención que busca Landaluze. En el siguiente fragmento se condensa esa inclinación al desorden y caos que se les asocia a los mataperros:

El malojero, el ciego que pide limosna, el negrito que vá tranquilo á su mandado ó la devota que sale muy despacio de la novena, todos sufren algo de la diabólica inventiva del mataperros: en fin, es perseguidor de cuanto no es él mismo (Hernández, 1881, p.154)².

Como podemos ver, hay una variedad considerable de símbolos que no aparecen ahí de una manera desinteresada: todos esos detalles son importantes para potenciar la carga con la que se les construye. Ahora, resulta interesante observar la manera en la que cuadros visuales y artículos costumbristas, tanto de México como de Cuba, establecen un diálogo bastante complejo. Si bien las características del lépero y del mataperros poseen diferencias socioculturales, tienen rasgos en común que permiten asociarlos. Sus diferencias radican en el contraste que presentan los artículos: Linati, empático; Hernández, incisivo, tomando en cuenta los comentarios mordaces que realiza de estos tipos sociales.

Si Linati buscaba encontrar la naturaleza propia del mexicano, también se interesó por asociar a los tipos sociales rasgos arraigados a una cultura poco civilizada, bajo una perspectiva letrada. Con "Tortilleras" (Figura 4) una manifestación visual muy sugerente para su análisis, Linati

\footnotetext{
${ }^{2}$ En la primera edición del libro, utilizada para este trabajo, hay un error con respecto a la numeración de las páginas. El número de la página señalado en el texto debería ser la 194. Sin embargo, en el texto aparece como 154.
} 
hace uso de esas técnicas anteriormente mencionadas e incluye algo representativo de México. Pero, además de proyectar ese aspecto relacionado con la cultura mexicana, introduce otros elementos que llena de predicaciones al grupo social de una manera extravagante.

\section{Figura 4}

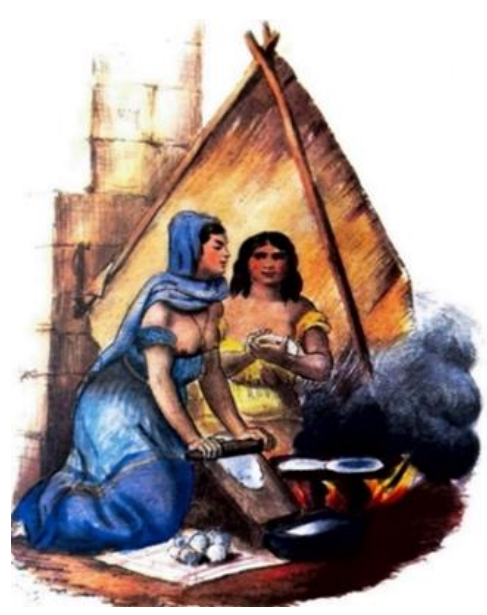

Claudio Linati. "Tortilleras". Extraído del libro Trajes civiles, militares y religiosos de México (p.41).

Es evidente que Linati ilustra a una de las tortilleras semidesnuda. Este aspecto puede ser asociado con la sensualidad. Sin embargo, no se manifiesta esa intención en primer término, aunque es posible percibir una ambigüedad texto-litografía que esconde un grado de morbo; es decir, la figura 4 tiene otra vertiente con respecto a la desnudez. En el análisis "El costumbrismo americano ilustrado: el caso peruano. Imágenes originales en la era de la reproducción técnica", Villegas Torres (2011, p.18), al hablar de litografía peruana, aprovecha y menciona un rasgo característico de Linati de la siguiente manera:

No se está lejos de satirizar la obra de la plebe urbana, vinculada a los oficios y heredera de las castas virreinales, al asociarla al proyecto ilustrado como sinónimo de atraso. Esta sería la mirada del italiano Claudio Linati, quien introdujo la litografía en México.

El desnudo en "Tortilleras", además de servir como un elemento sensual, sirve para denunciar una especie de atraso, como comenta Villegas, no solo político sino social. Esto puede ser considerado 
como poco civilizado, bajo una perspectiva de la época, en una nación que recientemente ha salido de un proceso de independencia. Lo anterior se complementa con el trabajo realizado en el suelo que desarrollan las tortilleras: si bien se busca el folclore mexicano, la litografía se abre a diferentes lecturas e interpretaciones. El artículo que acompaña a la ilustración no busca describirla a manera de écfrasis en este caso. Linati (1981) se inclina a describir el proceso de creación de una tortilla y los elementos que la conforman, además de mencionar el uso del pan que se extiende en la cultura mexicana. De nuevo, se puede ver una doble intención: se aprovecha la litografía para hablar de un aspecto cultural y representativo de México, mientras que la imagen se expresa con un lenguaje totalmente distinto al artículo. La intención de una y otra representación es claramente contrastante. Se establece un encuentro entre un elemento alarmante para un letrado de la época, el desnudo, y la enunciación de una tradición mexicana.

En el caso de Landaluze y de los artículos, la manera de caracterizar al sector afrocubano sobresale por un cierto apego al exotismo, al desorden y a la violencia. Se busca resaltar sus raíces africanas, principalmente lo que las asocian a su religión y los convierte en el otro. En el caso del ñáñigo o diablito (personaje afrocubano) se destaca, por obvias razones, la vestimenta alejada de los parámetros occidentales (Figura 5).

\section{Figura 5}

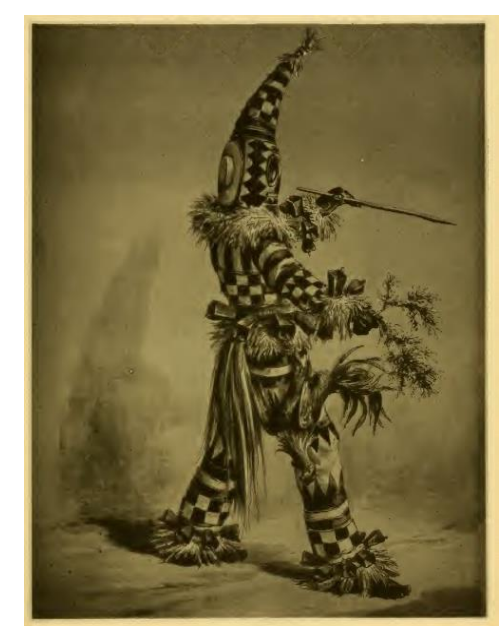

Víctor Patricio de Landaluze. "El ñáñigo". Extraído del libro Tipos y costumbres de la isla de Cuba (p. 141). 
Su exotismo es, sin duda, sugerente. Pero en este caso, el artículo que acompaña al cuadro visual, escrito por Enrique Fernández Carrillo, es sumamente llamativo. Además, complementa considerablemente la intención de Landaluze. Con respecto a por qué en el tiempo de la enunciación el ñañiguismo admite blancos, el autor menciona:

Quiere el ñañiguismo la degradación de una raza superior para conseguir el enaltecimiento de razas inferiores. Tiene el hombre apetitos desordenados y si no se halla cultivada su inteligencia, si no posée la educación, que regenera la humanidad, no hay trabas que le contengan. (Fernández, 1881, pp.143-144)

Hay una inclinación por parte de Fernández Carrillo por asociar una acción puramente violenta y vengativa, en este caso de los ñañigos, con un sector poblacional que no posee una voz. Se construye al personaje desde una perspectiva letrada. Es decir, el escritor aprovecha la litografía de Landaluze para configurarlos de una manera negativa. Además de adscribirles esas cargas, puede percibirse una advertencia: el miedo a la posibilidad del caos en la sociedad, de la que tanto se advierte en el siglo XIX.

Con respecto a los sectores afrocubanos, es necesario mencionar una de las pinturas más importantes de Landaluze: Día de reyes en La Habana (1886). La obra condensa, en gran parte, su perspectiva dirigida a la festividad y a la sección de la población que participa en ella. Es interesante la manera en la que los pintores aprovechan un día particularmente diferente a lo habitual. Con respecto a la fijación que realizan artistas como Federico Mialhe y Landaluze en esta clase de fiestas, Roberto González Echevarría (2010, p.72) menciona lo siguiente:

Es como si, con ojo de antropólogos, estos artistas pensaran que los grupos sociales se definieran con mayor puntualidad en actos no impuestos por la obligación, sino en aquellos organizados en horas de esparcimiento. Además, en esos ratos de recreo es cuando los grupos humanos despliegan su talento artístico en músicas, cantos, y bailes. 
Figura 6

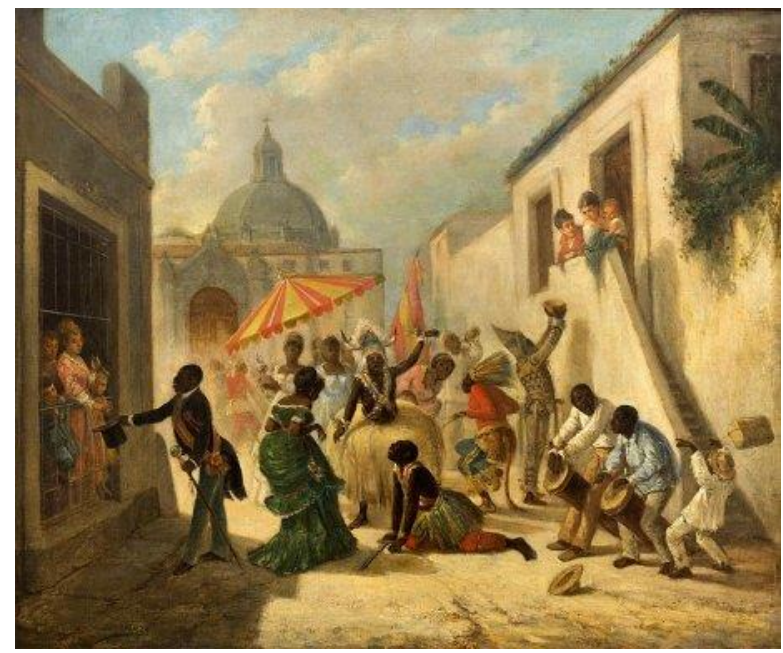

Víctor Patricio de Landaluze. Día de reyes en La Habana (1886). Imagen tomada de la página web del Museo Nacional de Bellas Artes de Cuba. http://www.bellasartes.co.cu/obra/victor-patricio-landaluze-dia-de-reyesen-la-habana.

Como se puede ver en la Figura 6, hay una cantidad considerable de aspectos que se prestan a una interpretación de desorden en la sociedad. Si bien los pintores se fijaban en los momentos de fiesta por la libertad con que se actúa en ella, hay una segunda intención dentro: Día de reyes en La Habana, también, construye una imagen caótica. La libertad que se observa no solo aporta folclore a la pintura sino, también, busca añadir una carga poco civilizada y, por ende, negativa. La integración del ñañigo, figura icónica, y otros rasgos como la vestimenta utilizada le aporta a la pintura una perspectiva de exotismo: se busca escindir a la sociedad en dos. La postura encorvada con que aparecen algunos personajes no se encuentra libre de una carga ideológica. Al no encontrarse parados de una manera erguida, se busca adjudicarles predicaciones peyorativas, por ejemplo, la intención de animalizar. La toma de las calles por la población marginada es, también, alarmante para el letrado del siglo XIX; es posible ver un subtexto en el cuadro de Landaluze: el desorden y el caos. A esta intención se suma el contraste del blanco en la pintura. Se distingue que, a pesar de estar en un mismo espacio, aparecen de una manera u otra, distanciados. Ya sea por las 
escaleras o por los barrotes de una ventana, la pintura de ninguna manera busca homogenizar; al contrario, se percibe la polarización: una distancia social. La vestimenta del blanco contrasta también con la de los afrocubanos. Como explica Reinstädler (2009), citado en Gómez (2010, p.122) con relación a las pinturas del día de reyes en la Cuba del siglo XIX: "Los negros aparecen como el abyecto Otro de la civilización caribeña, su cultura constituye una ofensa para la sensibilidad "blanca". La pintura se expresa a través de un lenguaje; sin embargo, también establece vasos comunicantes con otras manifestaciones artísticas, como la poesía". En el siguiente fragmento de un poema, cuyo título no se especifica, es posible percibir, al igual que en la pintura, una doble intención:

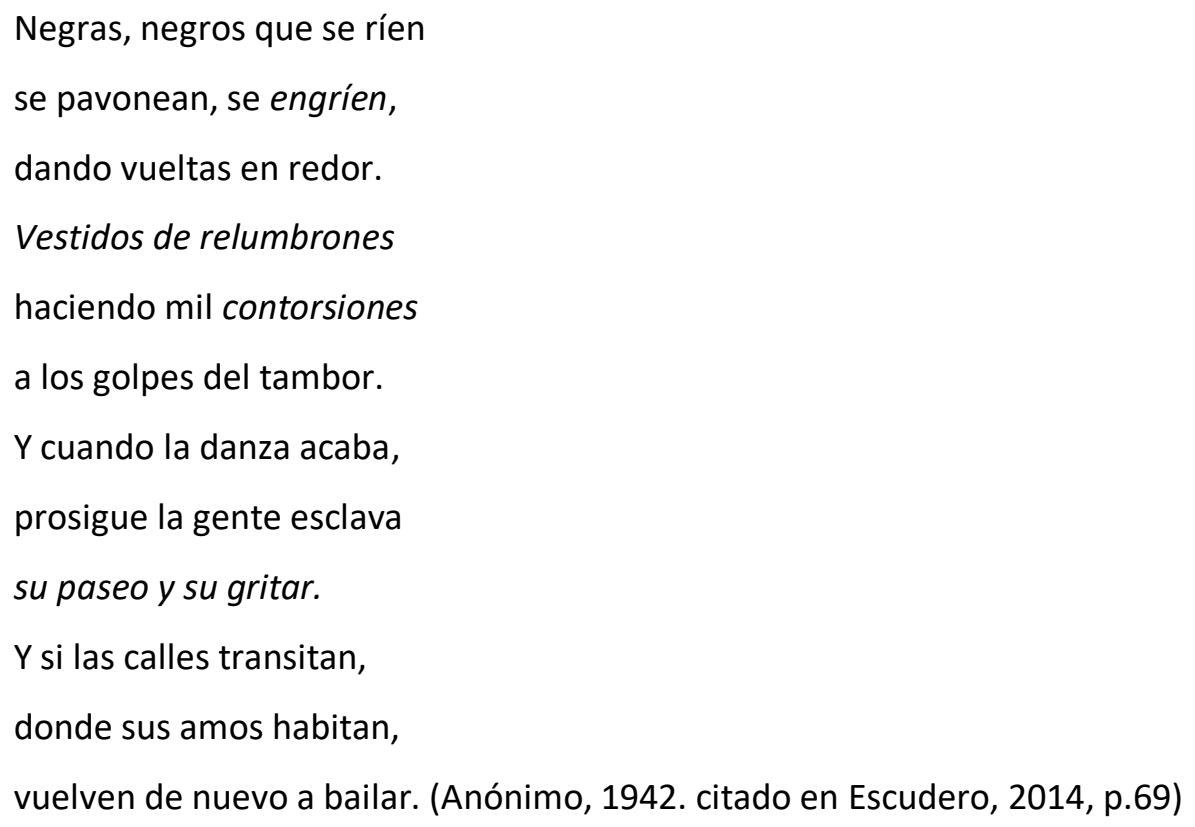

El poema, además de presentar una festividad apropiada por una parte de la sociedad, utiliza un lenguaje particular, elemento no exento de considerarse. Las palabras resaltadas buscan connotar, a través de la articulación, a la comunidad afrocubana del siglo XIX. Si en la pintura aparecen rasgos que ayudan a caracterizar con su representación artística a un grupo social, el poema también logra realizarlo desde sus posibilidades de expresión. Por lo tanto, ambas obras establecen un diálogo en 
el que se complementan una a la otra, sin distar en la mayoría de los casos, su intención primordial: el caos.

En el caso de México, la manera en que Linati caracteriza a la comunidad afrodescendiente es importante. Como menciona Pérez Benavides (2007, p. 1170) con relación a una de las intenciones que tenía el artista de la época: "los autores costumbristas pensaban en los tipos sociales como esencias y, dado el carácter instructivo que los inspiraba, sus relatos eran también lecciones morales que condenaban las malas costumbres y exaltaban las virtudes". La intención moralizante que comenta la autora se muestra claramente en la labor de Linati, especialmente, si se hace una comparación de "Negro de Veracruz" (Figura 7) y "Negro recostado en su hamaca" (Figura 8).

\section{Figura 7}

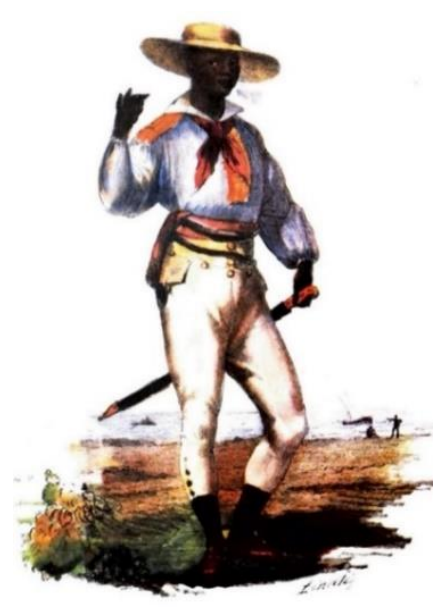

Claudio Linati. "Negro de Veracruz". Extraído del libro Trajes civiles, militares y religiosos de México (p.69). 


\section{Figura 8}

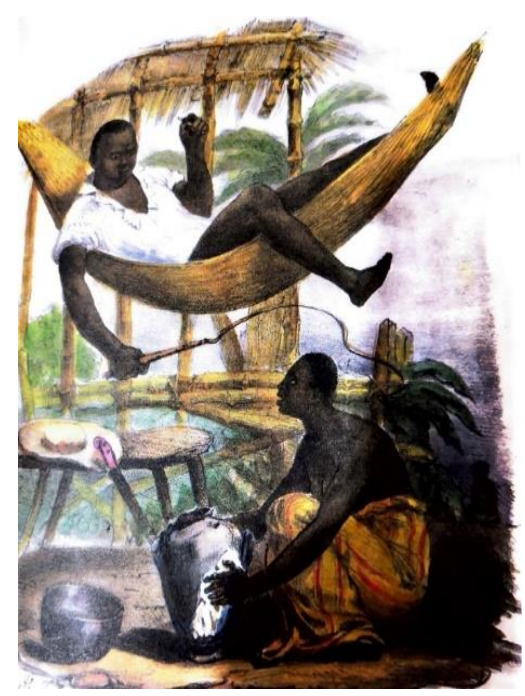

Claudio Linati. "Negro recostado en su hamaca". Extraído del libro Trajes civiles, militares y religiosos de México (p.141).

Entre ambas ilustraciones se presentan contrastes dignos de considerarse. La figura 7 muestra al negro de Veracruz que, aparentemente, se encuentra trabajando. El artículo que acompaña al cuadro lo describe con cariño, de la siguiente manera:

[...] diremos que la raza de los negros del golfo de México es superior a la de los indígenas, mestizos y criollos. Los negros son robustos, alegres y despiertos, mientras que aquí la raza europea es lánguida y débil y se propaga con dificultad [...] Les corresponden los trabajos más penosos, aquellos sin los cuales el hombre no podría prosperar. (Linati, 1981, p.68)

Como si el autor quisiera contrastar los dos cuadros, sitúa en la figura 8 un escenario totalmente distinto. De cierta manera, la herramienta punzocortante que utiliza el personaje de la figura 7 se encuentra justificada, debido a que se puede intuir que está trabajando por el fondo detrás de él. Su postura recta tiene una connotación positiva, al contrario de lo que se busca connotar en la figura 8 y en la figura 6, con relación a los afrodescendientes. Si bien el trabajador se ve alegre, no es de una 
manera excesiva sino completamente mesurada y pacífica. Todas estas implicaciones cargan al personaje, por el mismo hecho de trabajar y ser útil, de aceptación por el autor: artículo y litografía se comunican. El desorden se encuentra en la figura 8. Linati coloca objetos que, además de la fuerte crítica a la holgazanería, se pueden interpretar como complementos de desarreglo, violencia y ocio, símbolos tan penados para cargar negativamente al personaje. Por ejemplo, el látigo en manos de una persona acostada evidencia sus rasgos violentos, pues, ¿para qué podría utilizar un látigo alguien que no hace nada? El sombrero puesto en la silla, aunque puede interpretarse como incidental, podría señalar holgazanería. Para la perspectiva letrada, el negro debía trabajar justo como se observa en la figura 7. Aunado a esto, objetos como el machete se encuentran presentes en la imagen, dando a entender que le pertenece a uno de los dos individuos y no lo utiliza. El personaje que se encuentra debajo del de la hamaca parece tener impresión de miedo, lo cual tiene una implicación muy importante: permea la violencia tanto implícita como explícita. En el artículo correspondiente, Claudio Linati $(1981$, p.140) comenta lo siguiente con relación a la holgazanería del negro en la hamaca:

El negro liberado, balanceándose muellemente en su hamaca [...] se procura un largo fuete para despertar la actividad de su compañera, porque a ella reserva todas la [sic] penalidades del quehacer. [...] será necesario también que [el blanco] haga valer su superioridad para impedir que el negro liberado abuse de un bien que ha recuperado y abandone el cultivo [...].

El ocio es, como ya se ha mencionado, un aspecto bastante penalizado por los litógrafos y escritores costumbristas del siglo XIX. El autor utiliza la ilustración con una segunda intención, la de moralizar. Como podemos observar, se aprovechan dos obras para cargarlas de manera positiva y negativa, respectivamente. Si bien se les reconoce que son trabajadores y alegres, se hace un contraste cuando aparece el ocio y el descanso como aspectos de las comunidades afrodescendientes. Se podría decir que las litografías y artículos de Linati poseen una ambivalencia que enriquece su estudio: no hay una sola manera de representar a un sector. Se observa que las expresiones 
artísticas de un mismo autor tienen distintas maneras de comunicarse: poseen diferentes lenguajes que complejizan sus interpretaciones y análisis.

Los campesinos cubanos, también llamados guajiros (Figura 9), forman parte de los muchos colectivos sociales ilustrados por Landaluze en Tipos y costumbres de la isla de Cuba. En ella aparecen algunos individuos que conviven entre sí. Aunque aparentemente no se muestran elementos que se asocian a una perspectiva letrada-conservadora, Landaluze sugiere algunos aspectos relacionados a esa lectura.

Figura 9

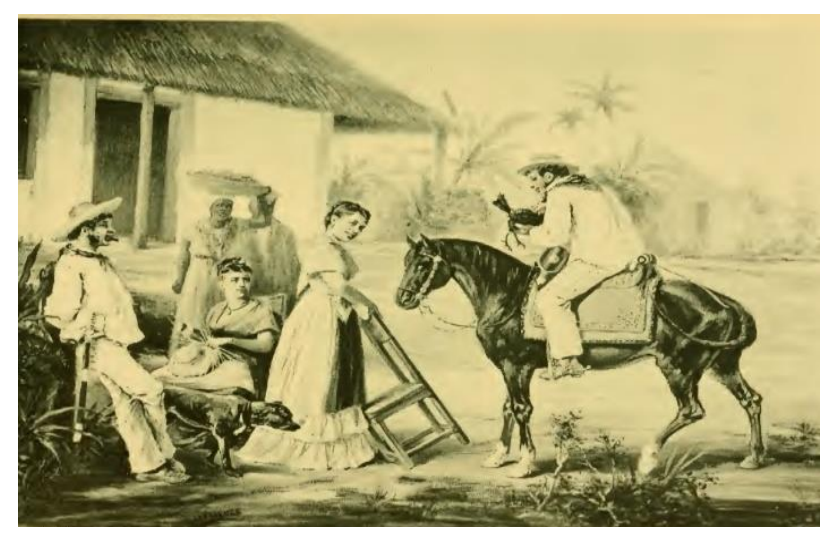

Víctor Patricio de Landaluze. "Los guajiros". Extraído del libro Tipos y costumbres de la isla de Cuba (p.56).

Es posible ver, por ejemplo, a la figura del perro que, como ya se ha comentado, implica relaciones estrechas entre un animal y una comunidad específica. Es curioso que aparezca en distintos cuadros visuales del siglo XIX acompañando a grupos, en su mayoría, marginados. El elemento punzocortante, si no está siendo utilizado, tiene connotaciones violentas, especialmente si el que lo utiliza habita alejado a la urbanización, como los guajiros. El artículo de costumbres que acompaña a la imagen fue escrito por J.Q. Suzarte. De manera similar a las relaciones entre artículo y litografía anteriormente referenciadas, el escrito complementa a la ilustración. A pesar de reconocer que 
eran simpáticos no deja de atribuirles lo problemáticos que eran en los "guateques", nombre que le daban a los bailes a los que acudían (1881). Con referencia a esta celebración se menciona:

[...] [los guateques] concluían mal frecuentemente: un gran celoso ó despreciado, un guajiro de otro partido que se creia ofendido por los conceptos de una de las décimas cantadas, tiraba repentinamente del machete, hacía pedazos con él los faroles en que ardian las tristes velas de sebo [...] y con las tinieblas comenzaba una zambra de dos mil demonios, de la que resultaban contusos, heridos y aun muertos, por lo comun involuntariamente, pues nadie sabia á quien atacaba ni de quien se defendía. (1881, p.56)

Suzarte no sitúa a los guajiros en una posición tan desaprobatoria como sí, de manera alarmante, Hernández coloca a los mataperros. Sin embargo, a pesar de reconocerle más aspectos positivos, no es tan polarizada su articulación. El autor también denuncia las características negativas atribuidas, pues no hay que olvidarse de que es una representación y no un calco o un retrato.

\section{Conclusión}

Resulta de verdadera importancia analizar cómo son las manifestaciones artísticas, tanto en aspectos visuales como literarios, no solo de sectores marginados sino de cualquier tipo social. Si bien las expresiones del costumbrismo de distintas tradiciones como el cubano y el mexicano poseen elementos que se relacionan, también son claros los contrastes y las maneras en las que tratan a los distintos grupos.

El caos, el desorden y la violencia se muestran, de manera explícita o implícita, en las litografías y pinturas de Claudio Linati y Víctor Patricio de Landaluze. Sin embargo, hay ciertos matices, como los que se han mencionado en el desarrollo de este trabajo, que pueden ser material de diálogo y contraste; de ahí viene también su importancia. Los encuentros visual-literarios parecen ser en Linati mucho más evidentes de lo que son con Landaluze y la variedad de articulistas y poetas que dialogan con su tradición. Sin embargo, es posible afirmar que hay una simiente, tanto en Cuba como en México del siglo XIX, de interpretar a la población marginal con hábitos y 
costumbres negativas. Como se ha analizado, puede ser por la búsqueda de un folclore o por la intención de asociar a estos tipos sociales con sus raíces prehispánicas. Existen muchas implicaciones que poseen las afirmaciones que se dan tanto en literatura como en pintura y litografía.

Es importante, además, mencionar la distancia temporal entre la productividad artística de Linati con la de Landaluze. Lo relevante de este lapso es la funcionalidad del costumbrismo en distintos sectores de Hispanoamérica. Establecer un diálogo entre las obras artísticas de dos culturas y tiempos distintos es de suma importancia para comprender el desarrollo del fenómeno. Este abarca a distintas disciplinas; sin embargo, en lo que respecta al campo de la interpretación y encuentro entre dos culturas, resulta de un valor considerable, además de ser una vertiente sugerente para su análisis.

\section{Referencias}

Bachiller, A., y de Landaluze, V. P. (1881). Tipos y costumbres de la isla de Cuba. La Habana: Miguel de Villa. Bobadilla, G. F. (2013). Literatura y cultura mexicana del siglo XIX: Lecturas y relecturas críticas e historiográficas. Hermosillo: Universidad de Sonora.

De Landaluze, V.P. (1886). Día de reyes en la Habana. Museo Nacional de Bellas Artes de Cuba. Recuperado de http://www.bellasartes.co.cu/obra/victor-patricio-landaluze-dia-de-reyes-en-la-habana.

Escudero, M. (2014). “El Día de Reyes” de Federico Mialhe: La importancia del grabado para el estudio de la iconografía musical cubana decimonónica. Cuadernos de iconografía musical, vol. 1 (1), 61-89.

Gómez, L. (2010). El discurso colonial en la iconografía cubana: Paisaje, urbanización y narrativas de lo rural del siglo XIX. G. Müller \& E. Ottmar (Eds.), Caleidoscopios coloniales: Transferencias culturales en el Caribe del siglo XIX, (pp.121-138). Madrid: Iberoamericana Editorial.

González, R. (2010). Fiestas y origen de la nación cubana. G. Müller \& E. Ottmar (Eds.), Caleidoscopios coloniales: Transferencias culturales en el Caribe del siglo XIX, (pp.67-81). Madrid: Iberoamericana Editorial.

Linati, C. (1981). Trajes civiles, militares y religiosos de México (Edición Facsimilar) Librería Manuel Porrua, S.A., Librería 1981. 
Peñas, Ana. (2011). Entre literatura y pintura: poética pictórica del artículo de costumbres. B. Rodríguez \& R. Gutiérrez (Eds.), Literatura ilustrada decimonónica: 57 perspectivas, (pp.625-638). Cantabria: PUbliCan, Ediciones de la Universidad de Cantabria.

Pérez, A. (2007). Actores, escenarios y relaciones sociales en tres publicaciones periódicas mexicanas de mediados del siglo XIX. Historia Mexicana, vol. LVI (4), 1163-1199.

Rodríguez, O. M. (1998). Landaluze: Pintor de costumbres. Anales del museo de América, (6), 85-93.

Villegas, F. (2011). El costumbrismo americano ilustrado: el caso peruano. Imágenes originales en la era de la reproducción técnica. Anales del museo de América (19), 7-67. 